\title{
Anti-Lethal Therapy of COVID-19 for Home Health Outpatient Therapy
}

\author{
Oleg Bukhtoyarov and Denis Samarin
}

\section{ABSTRACT}

\begin{abstract}
The article presents the rationale for a new therapeutic strategy for treatment of patients with COVID-19, based on the combined use of biologic response modifiers and drugs targeting etiology and pathophysiology of the novel coronavirus infection, excluding disadvantages of polypharmacy, and providing a high clinical effect. This approach has been predominantly used in home health outpatient treatment of 324 patients with COVID-19 of variable severity using the biologic response modifiers "double drug cocktail" made of recombinant human interleukin-2 and recombinant human interferon alpha-2b in combination with alimemazine, nimesulide, rivaroxaban and antibiotic therapy (co-amoxiclav, or ceftriaxone) if secondary bacterial pneumonia was diagnosed. The results obtained indicate a dramatic improvement in the condition of patients, even with a severe COVID-19, which made possible to avoid artificial ventilation and prevent deaths.
\end{abstract}

Keywords: Anti-lethal therapy, COVID-19, Cytokines, Interleukin-2, Interferon alpha-2b, Outpatient treatment.

\author{
Submitted : June 30, 2021 \\ Published : July 23, 2021 \\ ISSN: $2593-8339$ \\ DOI: $10.24018 /$ ejmed.2021.3.4.960 \\ Dr. Oleg Bukhtoyarov* \\ Medical Center 39 Ltd, Kaliningrad, \\ Russian Federation. \\ (e-mail: bukhtoyarov@mail.ru) \\ Dr. Denis Samarin \\ Laboratory of Psychoimmunology, \\ Medical Center 39 Ltd, Kaliningrad, \\ Russian Federation. \\ (e-mail: d.m.samarin@ngs.ru)
}

*Corresponding Author

\section{INTRODUCTION}

The coronavirus disease (COVID-19) pandemic caused by severe acute respiratory syndrome coronavirus-2 (SARSCoV-2) led to occurrence of 181521067 COVID-19 cases and 3937437 global deaths as of 30 June 2021 [1]. COVID19 pandemic caught by surprise healthcare systems of all countries around the globe. Due to lack of scientific evidence, it especially appeared in the empirical approach to the treatment of patients with COVID-19 polypharmacy, and in the constant change of potential drug candidates for COVID19 therapy. Some drugs were not effective enough, like azithromycin [2], while others (for example, heparin, chloroquine, etc.) turned out to be unsafe for patients because they had numerous side effects in the hematopoietic and cardiovascular systems [3]. Treatment of COVID-19 patients with underlying chronic diseases (diabetes mellitus, cardiovascular diseases, etc.) presents significant difficulties [4].

The outcome of COVID-19 in each individual patient depends on the predominance of the mechanisms of etiopathogenesis (the onset and development of the disease) and sanogenesis (self-healing of the body) [5]. These mechanisms are closely related, but opposite in their biological orientation. It is logical to argue that a high therapeutic effect can be achieved with an etiopathogenetically and sanogenetically oriented approach to handling patients with COVID-19. In this regard, the following etiopathogenetic mechanisms of COVID-19 are of particular importance for the development of therapeutic strategies: direct viral toxicity, endotheliopathy, hypercoagulability, vasculitis, immune system dysregulation with non-specific hyperinflammatory state (cytokine storm), maladaptation of the angiotensin-converting enzyme-2 (ACE2) pathway [6], [7].

A terrible complication of severe COVID-19 is acute respiratory distress syndrome with multiple organ failure [8]. The impossibility of quick discovery and production of new drugs for the treatment of COVID-19 has led to a revision of indications for already known drugs in the treatment of other diseases, thereby realizing a drug repurposing strategy [9], [10]. This strategy has resulted in dozens of candidate drugs for the treatment of COVID-19 from various pharmacological groups [11], [12]. In our opinion, all candidate drugs from this large list are exclusively etiopathogenetically and symptomatically oriented with "anti-" effects, but there are no drugs with biologic response modifiers effects, i.e., with natural sanogenetic "self-repair" effects in it. The US National Institutes of Health (NIH) presented, in our opinion, a number of drugs for sanogenetic therapy of COVID-19 from the group of biologic response modifiers: interferons (IFN alfa-2b, IFN beta-1a, IFN beta-1b) and non-SARSCoV-2 specific immunoglobulin [13].

Currently, we observe that the long-forgotten sanogenetic therapy is reviving under the name of Low-dose medicine (LDM) [14].LDM is based on the use of fundamental biologically active molecules (cytokines, neuropeptides, hormones, growth factors), which are usually present in the body of a healthy person and regulate cellular and tissue metabolism. It should be noted, that the LDM treatment of COVID-19 also received theoretical justification [15].

We used two immunotherapeutic drugs in the sanogenetic therapy of COVID-19: recombinant human interleukin-2 (rhuIL-2) - Roncoleukin ${ }^{\circledR}$ (approved by order No. 249 of Ministry of Health, Russian Federation, August 31, 1995, Registration Certificate No. LS-001810, Research and Production Company BIOTECH, Ltd) and recombinant 
human interferon alpha-2b (rhIFN $\alpha-2 b) \quad-$ Viferon $\AA$ (approved by order No. 192 of Ministry of Health, Russian Federation, September 27, 1994, Registration Certificate No. 96/432/5, Pharmaceutical Company FERON, Ltd). The clinical results of our proposed therapeutic approach in the treatment of patients with COVID-19 mainly on an outpatient basis are presented in this work.

\section{A. Search Strategy and Selection Criteria}

We searched for scientific articles published before April 05, 2021, without language restrictions using the search engines Google, Google Scholar and electronic research databases PubMed / Medline, SCOPUS, Web of Science. Our search strategy used combinations of keywords including "SARS-CoV-2", "COVID-19", "Pathogenesis", "Inflammation", "IL-2", "IFN $\alpha-2 b ", \quad$ "Alimemazine", "Nimesulide", "Rivaroxaban", "Autonomic dysfunction", "Outpatient", "Treatment", "Neuro-COVID". We also reviewed papers prepared by the World Health Organization (WHO) and NIH (USA). Articles published primarily in 2020 and 2021 were included.

\section{New StRategy FOR Home Health OUtPatient THERAPY OF COVID-19: OUR RESULTS}

\section{A. Patients}

From May 11, 2020 to February 07, 2021, 324 patients (166 women and 158 men) aged 6-84 years with a confirmed diagnosis of COVID-19 (PCR detection of SARS-CoV-2 RNA in respiratory samples) were treated in accordance with our recommendations in the following regions: Germany (Trossingen) - four; Italy (Bellamonte - three, Moena three); Kazakhstan (Baikonur) - 20; Republic of Belarus (Rechytsa) - five; Russian Federation (Moscow - 52, St. Petersburg - 21, Kaliningrad - 138, Kemerovo - five, Nizhny Novgorod - 15, Omsk - six, Orenburg - eight, Samara - 32, Stavropol - six); Switzerland (Sankt Gallen) - three; USA (Brooklyn Center, MN) - three.

319 patients received home health outpatient therapy of COVID-19: mild COVID-19 - 202 patients (without evidence of viral pneumonia or hypoxia, fever $<37.8^{\circ} \mathrm{C}$ ), moderate COVID-19 - 104 patients ( 75 patients with clinical symptoms of viral pneumonia: fever $>38{ }^{\circ} \mathrm{C}$, chills, respiratory rate $>22$ breaths / $\mathrm{min}$, dyspnoea, nonproductive cough, rhinitis, myalgias, headaches, fatigue, but no signs of severe pneumonia; 29 patients with clinical symptoms of bacterial pneumonia: cough with mucus that is yellow, green, or tinged with blood, stitching chest pain in the that is worse when coughing or breathing and rigors), severe COVID-1913 patients (clinical signs of bacterial pneumonia, respiratory rate > 30 breaths / min, volume lung lesions 55-72\% according to computed tomography, blood saturation level $\left(\mathrm{SpO}_{2}\right)$ 90-75\%). All patients with severe COVID-19 were from Russia (Nizhny Novgorod - five, Kaliningrad - four, Samara - three, St. Petersburg - one). Five patients out of all these patients were treated in the intensive care unit.

Treatment of patients with moderate and severe COVID19 on an outpatient basis (at home) quite unexpectedly turned out to be a necessary measure. Practically, all patients and / or their relatives firmly refused hospitalization "for fear of dying in the hospital", as they witnessed deaths in the hospital among their relatives, acquaintances and friends. They sought help from Medical Center 39 Ltd (Kaliningrad), because they had information about the successful outpatient treatment of COVID-19. We accompanied the outpatient treatment of patients with remote consultations, except for seriously ill patients in Kaliningrad, who were provided with in-person outpatient care. We realized the full responsibility of the outpatient treatment of COVID-19 and warned patients about immediate inpatient treatment in case of the slightest deterioration in their condition. The first patient with successful outpatient home treatment according to our proposed protocol of moderate COVID-19 (Table I) was the wife of one of the authors of this article.

\section{B. Sanogenetic Regulatory Cytokine IL-2: Rationale for Use in Patients with COVID-19}

Interleukin-2 (IL-2) plays a key role in the regulation of specific immunological processes and is a vital, proliferative factor for lymphocytes, which retain their viability only when it is present [16]. A deficiency of IL-2 occurs in COVID-19 patients along with the death of a significant number of lymphocytes ( $T$ cells) [17], what leads to obstruction of specific immune responses, generalization of the infectious process and inflammation. In addition, with COVID-19, clones of lymphocytes responsible for tissue repair tend to survive, which is correlates with a high risk of autoimmune diseases development [18].

IL-2 plays a decisive role in the expansion of regulatory $\mathrm{T}$ cells (Tregs) that help establish a balance between defense against pathogens and avoidance of autoimmune disease [19].IL-2 deficiency leads to a decrease in Tregs and the development of fatal inflammatory and autoimmune diseases that can be suppressed by restoring the normal number of Tregs [20]. By the way, the number of Tregs inversely correlates with the severity of COVID-19 [21]. It is important to know that Tregs are 7-10 times more sensitive to IL-2 than natural killer (NK cells), therefore a "low dose" of IL-2 in the range of $1-3 \times 10^{6} \mathrm{IU} / \mathrm{m}^{2}$ body surface area / day reliably increases Tregs, but also increases the number of NK cells. If we reduce IL-2 to "ultra-low dose", i.e., 10 to 50 times, Tregs expansion continues, but with much less effect on NK cells [22]. Low doses of IL-2 selectively activate Tregs through an IL-2-dependent transcriptional amplification mechanism, which provides the molecular basis for low and ultra-low dose IL-2 therapy to achieve powerful anti-inflammatory effects and immune tolerance [23].

There is sufficient theoretical justification for the use of IL2 in the treatment of COVID-19 [24] and encouraging results have been obtained from the use of rhuIL-2 in addition to regular treatment of severe COVID-19 [25]. We used an ultra - low-dose of rhuIL-2 (Roncoleukin $\left.{ }^{\circledR}\right) 5 \times 10^{5} \mathrm{IU}$ for in home health outpatient therapy of COVID-19 (Table I). We deliberately used ultra-low-dose of rhuIL-2 (Roncoleukin ${ }^{\circledR}$ ) to avoid the risk of increased biological effector proinflammatory functions of CD4 T cells, CD8 T cells and NK cells [26], which could exacerbate the disease and increase autoimmunity.

\section{Sanogenetic Antiviral Cytokine IFNa-2b: Rationale for Use in Patients with COVID-19}

Type I interferons (IFNs), including IFN $\alpha-2 b$, are key elements of the immune response, the first line of defense of 
the immune system against infectious agents and tumor progression. A sufficient amount of interferons in the body leads to an accelerated maturation of cells of the immune system with a complete development of their protective functions, acting synergistically with IL-2 [27], [28]. However, SARS-CoV-2 inhibits the production of endogenous interferons with the rapid development of infection, the appearance of severe pulmonary and multiorgan lesions in COVID-19 [29]. IFNs deficiency, in particular IFN $\alpha$, is a distinctive feature of coronavirus infection, which is accompanied by a high viral load and a more severe course of COVID-19 [30], [31]. Moreover, IFNs production deteriorates significantly with age [32], which could be critical for elderly COVID-19 patients. At the same time, SARS-CoV-2 is highly sensitive to exogenously added interferons, in particular to rhIFN $\alpha-2 b$ [33].IFNs dosedependently inhibit the replication of the SARS-CoV-2 virus that making them good candidates for the management of COVID-19 [34].

IFN $\alpha-2 b$ is included in the WHO's list of essential medicines and is used for antiviral and anticancer therapy [35]. IFN $\alpha-2 b$ stimulates the expression of the ACE2 receptor in epithelial cells of the human nose and the SARS-CoV-2 virus binds precisely to the inactivated ACE2 receptor. Therefore, by increasing the expression of ACE2 receptors and translating them into an activated state, IFN $\alpha-2 b$ increases tolerance to SARS-CoV-2 [36]. IFN $\alpha-2 b$ therapy shortens the duration of SARS-CoV-2 release, reduces the level of markers of acute inflammation [37], prevents the severe course of COVID-19 [38] and reduces mortality in COVID-19 patients [39].

In our outpatient treatment protocols, we aimed to use rhIFN $\alpha-2 b$ (Viferon ${ }^{\circledR}$ ) as rectal suppositories as early as possible at a dosage of $3 \times 10^{6}$ IU once or twice a day, depending on the severity of COVID-19 (Table I), in order to prevent more severe course of COVID-19.

\section{Justification of the Need for Timely Treatment of Hypersympathicotonia in Patients with COVID-19}

The widely presented symptomatology is so called "neuroCOVID" [40], i.e. the neurological, psychiatric and psychological manifestations related to COVID-19, is due not only to psychogenic factors, but also neuroinflammation caused by direct and indirect neurotoxicity of SARS-CoV-2, high levels of pro-inflammatory cytokines IL-6, TNF- $\alpha$, IL$1 \beta$ in plasma, cerebrospinal fluid, brain of patients [41], [42]. As well as over-excitation of the sympathetic nervous system through its main neurotransmitter norepinephrine (also called noradrenaline) [43], which in turn leads to direct suppression of the antibacterial functions of neutrophils, forming higher susceptibility of patients to infectious complications [44].

Excessive sympathicotonia is a common pathophysiological feature in patients with hypertension, heart disease, diabetes and other diseases which present as comorbidities in COVID-19 patients, have a higher risk of developing life-threatening complications [45], including, for example, stress-induced cardiomyopathy - Takotsubo Syndrome [46]. Earlier, in experimental psychoneuroimmunological studies in oncology, it was convincingly shown that induced hypersympathicotonia led to a 30 -fold increase in metastases to distant tissues [47].
Thus, extreme sympathicotonia is a powerful factor in immunosuppression and generalization of the inflammatory process in patients with COVID-19, as well as an important target for therapeutic intervention.

For the relief of nosogenic reactions and excessive sympathicotonia in patients with COVID-19 (except for children), we used the antipsychotic medication alimemazine/trimeprazine (Teralidgen ${ }^{\circledR}$ ), which in a dosage of $5 \mathrm{mg} \mathrm{1}$, or 2 times a day proved to be an effective drug capable sufficiently and quickly discontinue anxiety-phobic symptoms and autonomic reactions in patients with COVID19, associated, for instance, with hypertension, hypotension, tachycardia, which were resistant to appropriate drug therapy. In addition, Teralidgen ${ }^{\circledR}$ showed a clinically balanced somnolent, sedative and antihistamine effect. Furthermore, in the experiment trimeprazine proved to be a promising inhibitor, of SARS-CoV-2 by blocking the viral penetration stage [48].

\section{E. Other Components of COVID-19 Anti-Lethal Outpatient Therapy}

We chose Rivaroxaban (Xarelto ${ }^{\circledR}$ ) at a dosage of $10 \mathrm{mg}$ once a day for the prevention of blood clots formation of the entire severity of COVID-19, because there was no need for the blood clotting control. Additionally, anticoagulant and antiplatelet therapy goes along with an anti-inflammatory effect [49].

In our clinical practice, we were convinced of the safety and efficiency of non-steroidal anti-inflammatory drugs nimesulide (Nise $\left.{ }^{\circledR}\right)$ with prolonged use (about a year), so we confidently used it in the COVID-19 treatment protocols. It is known that nimesulide abolishes the transport function of a broad spectrum of neutral (0) amino acid transporter B0AT1 (encoded by the SLC6A19 gene), which stabilizes the dimeric receptor ACE2-B0AT1, which is targeted by SARS-CoV-2 [50]. Thus, nimesulide probably also has an indirect antiviral activity.

Antibiotic therapy was used in $28 \%$ of patients with moderate COVID-19 (co-amoxiclav) only with clinical signs of secondary bacterial pneumonia and in all patients with severe COVID-19 (ceftriaxone) in whom bacterial coinfection is a high risk factor for mortality [51]. It is noteworthy that none of the diagnostic indicators such as procalcitonin and C-reactive protein has significant additional value in patients with COVID-19 for bacterial coinfection diagnosis comparing to clinical criteria [52].

\section{F. Clinical Effects and Treatment Outcomes}

The results of sanogenetic cytokine therapy with rhuIL-2, and rhIFN $\alpha-2 b$ in complex outpatient home treatment of patients with COVID-19 of varying severity turned out to be more than positive. 
TABLE I: THE SCHEME OF HOME HEALTH OUTPATIENT THERAPY OF COVID-19 AND POST-ACUTE COVID-19 SyNDROME

\begin{tabular}{|c|c|c|c|c|}
\hline Group & Drugs & Trademark & Mechanism of action & osing \\
\hline \multicolumn{5}{|l|}{ Mild COVID-19 } \\
\hline Immunomodulators & $\begin{array}{l}\text { Recombinant human } \\
\text { interleukin-2 } \\
\text { (from recombinant } \\
\text { strain of non- } \\
\text { pathogenic brewer's } \\
\text { yeast Saccharomyces } \\
\text { cerevisiae) } \\
\text { (Solution in } \\
\text { ampoules) }\end{array}$ & Roncoleukin ${ }^{\circledR}$ & $\begin{array}{l}\text { Vital growth and differentiation factor for antigen- } \\
\text { activated T-, B-lymphocytes, and NK cells; critical } \\
\text { survival / growth factor for FOXP } 3 \text { + regulatory T } \\
\text { cells; increases the production of IFN-gamma, etc.; } \\
\text { prevents apoptosis of activated T-lymphocytes; } \\
\text { increases the synthesis of IgM, IgG, IgA by plasma } \\
\text { cells; activates the processes of tissue repair and } \\
\text { regeneration; suppresses autoimmunity in low-dose. }\end{array}$ & $\begin{array}{l}\text { Day 1-6: } 5 \times 10^{5} \mathrm{IU} \\
\text { / every other day, } \\
\text { subcutaneously. }\end{array}$ \\
\hline
\end{tabular}

Immunomodulators Recombinant human $\quad$ Viferon ${ }^{\circledR}$ interferon alpha-2b with antioxidants (ascorbic acid, and $\alpha-$ tocopherol acetate) (Rectal suppositories)

\section{Direct oral} anticoagulant, factor Xa inhibitor

Rivaroxaban (Tablets)

Non-steroidal antiinflammatory drugs

Nimesulide (Tablets)

Neuroleptics

Alimemazine tartrat
(Tablets)

Teraligen ${ }^{\circledR}$ (Tablets)

\section{Moderate COVID-19}

Immunomodulators

Immunomodulators

Non-steroidal antiinflammatory drugs

Direct oral

anticoagulant, factor Xa inhibitor

Neuroleptics
Xarelto ${ }^{\circledR}$

Nise ${ }^{\circledR}$

(1)

Binds to type-1 interferon receptors, leading to the Day 1-10: $3 \times 10^{6}$ dimerization of JAK1 and JAK2 receptors, that leads IU/ daily bedtime, to JAK trans-phosphorylation, and phosphorylation of per rectum. STAT1 and STAT2. Dimerized STAT activates multiple antiviral proteins. Inhibits viral replication, viral proteases, increases phagocytic activity of the macrophages, and the specific cytotoxicity of lymphocytes. Accelerates the maturation of cells of the immune system, normalizes the antioxidant status and protease activity of blood plasma, enhancing antiviral and antiproliferative activity 10-14 times.

Direct, specific inhibition of endogenous factor Xa Day 1-10: $10 \mathrm{mg} /$ activity, potently inhibition prothrombinase activity, once a day, orally. inhibition of thrombin generation and amplification processes of coagulation, increasing the permeability and degradability of the whole blood clot by reducing the formation of thrombin.

Inhibition of cyclooxygenase COX-2,

Day 1-10: $100 \mathrm{mg} /$ phosphodiesterase type 4 , proteases (elastase, once a day, orally. proteinase), histamine release from human basophil, and mast cells; inhibition of histamine activity, and the synthesis, release of the substance $\mathrm{P}$; reduced generation of superoxide anion $\mathrm{O} 2$; scavenging of hypochlorous acid; activation of glucocorticoid receptor system.

Blockade of dopamine D2 receptors of the mesolimbic, Day 1-10: 2.5 or 5 and mesocortical systems (antipsychotic effect), mg/at night, blockade of $\mathrm{D} 2$ receptors in the trigger zone of the orally. vomiting center (antiemetic effect), blockade of adrenergic receptors of the reticular formation of the brain stem (sedation effect), blockade of dopamine receptors of the hypothalamus (hypothermic effect), blockade of agonist action of histamine at the $\mathrm{H} 1$ receptor (antihistamine effect), reducing the activity of the NF- $\mathrm{KB}$ immune response transcription factor through the phospholipase $\mathrm{C}$, and the phosphatidylinositol (PIP2) signalling pathways decreases antigen presentation and the expression of pro-inflammatory cytokines, cell adhesion molecules, and chemotactic factors (anti-inflammatory effect).

Recombinant human
interferon alpha- $2 b$
Nimesulide

Rivaroxaban

Alimemazine tartrat
Recombinant human Roncoleukin ${ }^{\circledR} \quad$ See above interleukin-2

Amoxicillin+clavula- Amoxiclav ${ }^{\circledR}$ nic acid (Co-

amoxiclav)

(Tablets)
See above

See above

See above

See above
Day 1-12: $5 \times 10^{5} \mathrm{IU} /$ every other day, subcutaneously.

Day 1-14: $3 \times 10^{6} \mathrm{IU} /$ twice a day, per rectum.

Day 1-14: $100 \mathrm{mg} /$ twice a day, orally.

Day 1-14: $10 \mathrm{mg} /$ once a day, orally.

Day 1-14: $5 \mathrm{mg} /$ at night, orally.

Amoxicillin binds to the penicillin-binding protein Day 1-5 (or 7): 875 enzyme and inhibits peptidoglycan synthesis by $\mathrm{mg}+125 \mathrm{mg} /$ twice destroying the cell wall and lysis of the bacteria. a day, orally. Clavulanic acid inhibits and deactivating the betalactamases, thus blocking hydrolyze the beta-lactam ring restoring the antimicrobial effects of amoxicillin. 


\begin{tabular}{|c|c|c|c|c|}
\hline Group & Drugs & Trademark & Mechanism of action & Dosing \\
\hline $\begin{array}{l}\text { Drugs normalizing of } \\
\text { intestinal microflora, } \\
\text { in combinations }\end{array}$ & $\begin{array}{l}\text { Bifidobacterium } \\
\text { longum } \\
\text { Enterococcus faecium } \\
\text { (Capsules) }\end{array}$ & Bifiform $\AA$ & $\begin{array}{l}\text { Probiotic activity provided by strains of bacteria } \\
\text { with a predictable high level of antibiotic resistance, } \\
\text { which actively colonize small, large intestine, and } \\
\text { produce acetic, lactic acid, thereby inhibiting the } \\
\text { growth, and reproduction of pathogenic } \\
\text { microorganisms. }\end{array}$ & $\begin{array}{l}\text { Day 1-14: one } \\
\text { capsule / three times a } \\
\text { day, orally. }\end{array}$ \\
\hline
\end{tabular}

\section{Sever COVID-19}

Immunomodulators

Recombinant human Roncoleukin ${ }^{\circledR} \quad$ See above interleukin-2

Immunomodulators

\section{Recombinant human} interferon alpha-2b

Non-steroidal antiinflammatory drugs

Direct oral anticoagulant, factor Xa inhibitor Neuroleptics

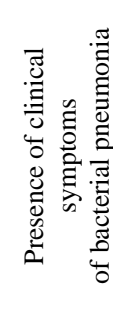

Third-generation

cephalosporin

antibiotic

Drugs normalizing of Bifidobacterium

intestinal microflora, longum

in combinations Enterococcus faecium

Post-acute COVID-19 syndrome (Long covid)

Immunomodulators

Recombinant human interleukin-2

Immunomodulators

Recombinant human interferon alpha-2b

Non-steroidal antiinflammatory drugs

Neuroleptics
Nimesulide

Alimemazine tartrat
Viferon ${ }^{\circledR}$

Nise $\mathbb{R}$

Xarelto ${ }^{\circledR}$

Teraligen $®$

See above
Bifiform ${ }^{\circledR} \quad$ See above

Binds, inactivates penicillin-binding proteins, and Day 1-7 (or 10): $2 \mathrm{~g}$ interferes with the cross-linkage of peptidoglycan vial with $0.9 \%$ chains necessary for bacterial cell wall strength and Sodium chloride rigidity. This results in the weakening of the injection $100 \mathrm{~mL} /$ bacterial cell wall and causes cell lysis. once a day, intravenously.

Day 1-14 (or 17): two capsules / twice a day, orally.

Day 1-60: $2.5 \times 10^{5} \mathrm{IU}$ / every other day, subcutaneously.

Day 1-30: $3 \times 10^{6} \mathrm{IU} /$ daily bedtime, per rectum.

Day 1-14: $100 \mathrm{mg} /$ twice a day, orally.

Day 1-30: $5 \mathrm{mg} /$ once or twice a day, orally.

With the beginning of therapy, not a single patient experienced a deterioration in health, there was no indications for artificial ventilation, and no single death, all patients recovered. Generally, hyperthermia disappeared on a second or third day with a remarkable clinical improvement in wellbeing in the following days and the reestablishment of the normal level of oxygen saturation. The complex therapy of patients with COVID-19 did not require the prescription of dexamethasone since the patients' well-being was steadily improving. Such a noticeable improvement in the well-being of patients has always been observed, including elderly patients with associated chronic diseases. Several children fell ill with mild COVID-19 along with their mothers; and all children were prescribed only rhIFN $\alpha-2 b$ at a dosage of $1 \times 10^{6}$ IU at night from the first day of illness. Within 7 days, all children completely recovered from COVID-19 and their well-being was returned.

We have obtained many clinical observations indicating the effectiveness of the proposed therapeutic approach. For example, a 54-year-old man (from Kaliningrad), a doctor with COVID-19 developed secondary cerebral vasculitis (sudden neurological deficit - paresis of the left foot, and neuropathy of the lateral cutaneous nerve of the left thigh; reduced visual acuity; diffuse headache; cognitive and affective disorders), and inflammatory cardiomyopathy, i.e. myocarditis (increase in the size of all the chambers of the heart, atrial extrasystoles with numerous episodes of allorhythmia (bi-, tri-, quadrigeminia). His signs of cerebral vasculitis, and myocarditis were completely stopped with the restoration of the normal size of the heart, heart rate, and wellbeing. With use of sanogenetic cytokine therapy rhuIL-2 $\left(2.5 \times 10^{5} \mathrm{IU} /\right.$ every other day, 30 subcutaneous injections $)$, and rhIFN $\alpha-2 \mathrm{~b}\left(3 \times 10^{6} \mathrm{IU}\right.$ morning and night, 20 days $)$ and alimemazine ( $5 \mathrm{mg}$ daily at night, 30 days), and nimesulide (100 $\mathrm{mg}$ twice a day for 20 days)

Two cases were clinical findings: significant regression of the parkinsonism syndrome, patients suffered for many years with the restoration of the ability to write and independently intake food was observed during treatment with rhuIL-2, and rhIFN $\alpha-2 b$ in an 82-year-old woman (from Samara), and a 74-year-old man (from Kaliningrad), in addition to the complete relief of moderate COVID-19 symptoms. The clinical effect was detected for three weeks, followed by the return of the previous symptoms of parkinsonism. 
The effective use of sanogenetic cytokine therapy in the treatment of COVID-19 was the basis for using this approach in the treatment of the so-called "Post-acute COVID-19 syndrome" (PACS), or "Long covid", the alleged pathogenesis of which is associated with direct infection with SARS-CoV-2, inflammation, autoimmune response, hypercoagulability, metabolic or hypoxic damage [53], [54], as well as in our opinion, a pathological state of the immune system referred to as homeostatic proliferation [55]. Almost all patients who came to us with PACS symptoms have received prior COVID-19 treatment in other medical institutions. PACS symptoms appeared 10-14 weeks after the onset of the disease, were very persistent and heterogeneous: hyposmia/dysgeusia, cognitive disturbances, anxiety, fatigue, arterial hypertension, etc.

A feature of our proposed PACS therapy was the half dosage of rhuIL-2, and rhIFN $\alpha-2 b$ (compared to dosages in the treatment of COVID-19) and a longer duration of therapy (from 20 to 60 days) in combination with appropriate symptomatic, and pathogenetic treatment PACS (table 1), in fact, has proven to be more resistant to therapy than COVID19 itself. Among the patients whom we previously treated with COVID-19, only seven people $(2.2 \%)$ presented with PACS symptoms.

\section{CONCLUSION}

Despite the emergence of different COVID-19 vaccines, the race for therapies for COVID-19 is steadily accelerating [56], but efficacy and safety should be paramount in treatment protocols. Our clinical experience has shown that the sanogenetic cytokine "double drug cocktail" of rhuIL-2, and rhIFN $\alpha-2 b$ is an important and safe clinical add-on into any treatment protocol for patients with COVID-19 of any severity, which allows it to have a decisive influence on the course of COVID-19, significantly improving the condition of patients, preventing the development of complications of coronavirus disease and the onset of death. A reasonable combination of sanogenetically, and etiopathogenetically oriented drugs, excluding disadvantages of polypharmacy, represents a new view and a promising therapeutic approach in the treatment of patients with COVID-19.

\section{LIMITATIONS}

We did not initially plan to conduct scientific research, so our work in the context of the COVID-19 pandemic was exclusively clinical. In this regard, it has several limitations that must be considered when interpreting the results and conclusions. First, this work is not a randomized controlled trial (RCT), and therefore does not belong to the "golden standard" of clinical trials. Second, all clinical work and its results are descriptive, phenomenological, so there is an obvious potential for publication bias. This work provides a clinical benchmark for future targeted RCTs that will contribute to the overall COVID-19 treatment efforts.

\section{ACKNOWLEDGMENT}

We express our deep gratitude to highly qualified nurse Natalya Kucher for her hard work, professionalism, and dedication in working with COVID-19 patients on an outpatient basis in Kaliningrad. We would like to thank Andrei Kovalevskii for his help in Russian-English translation of this article.

\section{SOURCE OF FUNDING}

The research was funded by the authors.

\section{CONFLICT OF INTEREST}

The authors declare that there are no conflicts of interest.

\section{REFERENCES}

[1] WHO Coronavirus (COVID-19) Dashboard. https://covid19.who.int Date: June 30, 2021. Date accessed: June 30, 2021.

[2] RECOVERY Collaborative Group. Azithromycin in patients admitted to hospital with COVID-19 (RECOVERY): a randomised, controlled, open-label, platform trial. Lancet. 2021;397:605-612.

[3] Aygün İ, Kaya M, Alhajj R. Identifying side effects of commonly used drugs in the treatment of Covid 19. Sci Rep. 2020;10:21508.

[4] Dai S-P, Zhao X, Wu J-H. Effects of comorbidities on the elderly patients with COVID-19: clinical characteristics of elderly patients infected with COVID-19 from Sichuan, China. J Nutr Health Aging. 2021;25:18-24.

[5] Pavlenko S.M. Pathogenesis and sanogenesis of disease. Ter Arkh. 1965;37(in Russian):115-122.

[6] Ashraf UM, Abokor AA, Edwards JM, et al. SARS-CoV-2, ACE2 expression, and systemic organ invasion. Physiol Genomics. 2021;53:51-60.

[7] Qin C, Zhou L, Hu Z, et al. Dysregulation of immune response in patients with COVID-19 in Wuhan, China. Clin Infect Dis. 2020;71:762-768.

[8] Mangalmurti N, Hunter CA. Cytokine storms: understanding COVID19. Immunity. 2020;53:19-25.

[9] Khan S, Siddique R, Shereen MA, et al. Emergence of a novel coronavirus, severe acute respiratory syndrome coronavirus 2: biology and therapeutic options. J Clin Microbiol. 2020;58:e0187-20.

[10] Kupferschmidt K, Cohen J. Race to find COVID-19 treatments accelerates. Science. 2020;367:1412-1413.

[11] Kouznetsov VV. COVID-19 treatment: much research and testing, but far, few magic bullets against SARS-CoV-2 coronavirus. Eur J Med Chem.2020;203:112647.

[12] Vougogiannopoulou K,Corona A, Tramontano E, Alexis MN, Skaltsounis A-L. Natural and nature-derived products targeting human coronaviruses. Molecules. 2021;26:448.

[13] National Institutes of Health. Characteristics of immunomodulators under evaluation for the treatment of COVID-19. https://www.covid19treatmentguidelines.nih.gov/tables/table-4b Date: February 21, 2021. Date accessed: April 05, 2021.

[14] Bernasconi S. Low dose medicine: theoretical background and scientific evidence. Ital J Pediatr. 2018;44:23.

[15] Ratheesh M, Sheethal S, Jose SP, et al. Biochemical and immunological aspects of COVID-19 infection and therapeutical intervention of oral low dose cytokine therapy: a systematic review. Immunopharmacol Immunotoxicol. 2021;43:22-29.

[16] Kelly E, Won A, Refaeli Y, Van Parijs L. IL-2 and related cytokines can promote T cell survival by activating AKT. J Immunol. 2002;168: 597-603.

[17] Bo Diao CW, Tan Y, Chen $X$, et al. Reduction and functional exhaustion of $\mathrm{T}$ cells in patients with coronavirus disease 2019 (COVID-19). Front Immunol.2020;11:1-7.

[18] Ehrenfeld M, Tincani A, Andreoli L, et al. Covid-19 and autoimmunity. Autoimmun Rev. 2020;19:102597.

[19] Sakaguchi S, Miyara M, Costantino CM, et al. FOXP3+ regulatory T cells in the human immune system. Nat Rev Immunol. 2010;10:490500 . 
[20] Spence A, Klementowicz JE, Bluestone JA, Tang Q. Targeting Treg signaling for the treatment of autoimmune diseases. Curr Opin Immunol. 2015;37:11-20.

[21] Wei LL, Wang WJ, Chen DX, Xu B. Dysregulation of the immune response affects the outcome of critical COVID-19 patients. J Med Virol.2020;92:2768-2776.

[22] YuA, SnowhiteI, VendrameF, et al. Selective IL-2 responsiveness of regulatory $\mathrm{T}$ cells through multiple intrinsic mechanisms supports the use of low-dose IL-2 therapy in type 1 diabetes. Diabetes. 2015;64:2172-2183.

[23] Boyman O, Sprent J. The role of interleukin-2 during homeostasis and activation of the immune system. Nat Rev Immunol. 2012;12:180-190.

[24] YazanA.Interleukin-2 level for normal people and COVID-19 infection: is it our concern is COVID-19 infection or interleukin-2 level before the infection? EJMO. 2021;5:1-5.

[25] Zhu M-E, Wang Q, Zhou S, Wang B, Ke L, He P. Recombinant interleukin-2 stimulates lymphocyte recovery in patients with severe COVID-19. Exp Ther Med. 2021;21:227.

[26] Sakaguchi S, Yamaguchi T, Nomura T, et al. Regulatory T cells and immune tolerance. Cell. 2008;133:775-787.

[27] Teijaro JR. Type I interferons in viral control and immune regulation. Curr. Opin. Virol.2016;16:31-40.

[28] El-LababidiRM, MootyM, BonillaM-F, SalemNM. Treatment of severe pneumonia due to COVID-19 with peginterferon alfa 2 a IDCases. 2020;21:e00837.

[29] Acharya D, Liu G, Gack MU. Dysregulation of type I interferon responses in COVID-19. Nat Rev Immunol. 2020;20:397-398.

[30] MeffreE, Iwasaki A. Interferon deficiency can lead to severe COVID. Nature. 2020;587:374-376

[31] Lucas C, Wong $\mathrm{P}$, Klein $\mathrm{J}$, et al. Longitudinal analyses reveal immunological misfiring in severe COVID-19. Nature. 2020;584:463469.

[32] Agrawal A. Mechanisms and implications of age-associated impaired innate interferon secretion by dendritic cells: a mini-review. Gerontology. 2013;59:421-426.

[33] Mantlo E, Bukreyeva N, Maruyama J, Paessler S, Huang C. Antiviral activities of type I interferons to SARS-CoV-2 infection. Antiviral Res.2020;179:104811.

[34] Felgenhauer U, Schoen A, Gad HH, et al. Inhibition of SARS-CoV-2 by type I and type III interferons. J Biol Chem. 2020;295:13958-13964.

[35] Landowski CP, Mustalahti E, Wahl R. Enabling low cost biopharmaceuticals: high level interferon alpha-2b production in Trichoderma reesei. Microb Cell Fact. 2016;15:104.

[36] Ziegler CGK, Allon SJ, Nyquist SK, et al. SARS-CoV-2 receptor ACE2 is an interferon stimulated gene in human airway epithelial cells and is enriched in specific cell subsets across tissues. Cell. 2020;181:1016-1035.e19.

[37] Yoshikawa T, Hill TE, Yoshikawa N, et al. Dynamic innate immune responses of human bronchial epithelial cells to severe acute respiratory syndrome-associated coronavirus infection. PLoS One. 2010;5:e8729.

[38] Zhou Q, Chen V, Shannon CP, et al. Interferon- $\alpha 2 b$ treatment for COVID-19. Front Immunol. 2020;11:1061.

[39] Baden LR, Rubin EJ. Covid-19 - the search for effective therapy. $N$ Engl J Med. 2020;382:1851-1852.

[40] TanchevaL, Petralia MC, MitevaS. Emerging neurological and psychobiological aspects of COVID-19 infection. Brain Sci. 2020;10:852.

[41] Steardo LJr, Steardo L, Verkhratsky A. Psychiatric face of COVID-19. Transl Psychiatry. 2020;10:261.

[42] Coomes EA, Haghbayan H. Interleukin-6 in COVID-19: a systematic review and meta-analysis. Rev Med Virol.2020;30:1-9.

[43] Tsatsakis A, Calina D, Falzone L. SARS-CoV-2 pathophysiology and its clinical implications: An integrative overview of the pharmacotherapeutic management of COVID-19. Food Chem Toxicol. 2020;146:111769.

[44] Nicholls AJ, Wen SW, Hall P, Hickey MJ, Wong CHY. Activation of the sympathetic nervous system modulates neutrophil function. $J$ Leukoc Biol.2018;103:295-309.

[45] Del Rio R, Marcus NJ, Inestrosa NC. Potential role of autonomic dysfunction in Covid-19 morbidity and mortality. Front Physiol.2020;11:561749.

[46] Shah RM, Shah M, Shah S, Li A, Jauhar S. Takotsubo syndrome and COVID-19: associations and implications. Curr Probl Cardiol. 2021;46:100763.

[47] Sloan EK, Priceman SJ, Cox BF, et al. The sympathetic nervous system induces a metastatic switch in primary breast cancer. Cancer Research. 2010;70:7042-7052.
[48] L, Pei R-j, Li H, et al. Identification of SARS-CoV-2 entry inhibitors among already approved drugs. Acta Pharmacol Sin. 2020; (published online Oct 28.) https://doi.org/10.1038/s41401-020-00556-6.

[49] GodinoC, ScottiA, MaugeriN, et al. Antithrombotic therapy in patients with COVID-19? - Rationale and evidence. Int J Cardiol. 2021;324:261-266.

[50] Scalise M, Indiveri C. Repurposing Nimesulide, a potent inhibitor of the B0AT1 subunit of the SARS-CoV-2 receptor, as a therapeutic adjuvant of COVID-19.SLAS Discov. 2020;25:1171-1173.

[51] Zhou F, Yu T, Du R, et al. Clinical course and risk factors for mortality of adult inpatients with COVID-19 in Wuhan, China: a retrospective cohort study. Lancet (London, England). 2020;395:1054-1062.

[52] Sieswerda E, de Boer MGJ, Bonten MMJ, et al. Recommendations for antibacterial therapy in adults with COVID-19 - an evidence based guideline. Clin Microbiol Infect. 2021;27: 61-66.

[53] Greenhalgh T, Knight M, A'Court C, Buxton M, Husain L. Management of post-acute covid-19 in primary care. BMJ. 2020;370:m3026.

[54] Moreno-Pérez O, Merino E, Leon-Ramirez J-M, et al. Post-acute COVID-19 syndrome. incidence and risk factors: a Mediterranean cohort study. J Infect. 2021;82:378-383.

[55] Boyman O, Létourneau S, Krieg C, SprentJ. Homeostatic proliferation and survival of naïve and memory $\mathrm{T}$ cells. Eur $J$ Immunol. 2009;39:2088-2094.

[56] Kupferschmidt K, Cohen J. Race to find COVID-19 treatments accelerates. Science.2020;367:1412-1413.

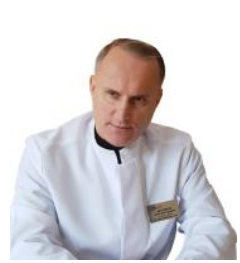

Oleg V. Bukhtoyarov was born 07.06.1966 in Rudny, Kazakhstan (USSR). Graduated from the S.M. Kirov Military Medical Academy in 1990 in Leningrad (now Saint Petersburg). MD in Psychoimmunology of cancer from the S.M. Kirov Military Medical Academy, 2012. The owner and chief physician of the Medical Center 39 Ltd, Kaliningrad, Russian Federation. Member of the Russian Society of Immunology.

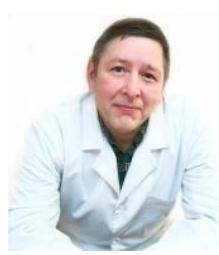

Denis M. Samarin was born 22.07.1964 in Novosibirsk, USSR. Graduated from the Tomsk Military Medical Faculty at the Siberian State Medical University in 1987. PhD in Immunology from the Research Institute of Clinical Immunology SB RAMS, Novosibirsk, 1996. Head of the Laboratory of Psychoimmunology, Medical Center 39 Ltd, Kaliningrad, Russian Federation. Member of the Russian Society of Immunology. 